\title{
O teatro no campo do real: estudo de caso em $100 \%$ São Paulo
}

\section{The theater in the real field: a case study in $100 \%$ São Paulo}

Lisandro Pires Bellotto $^{1}$

Marta Isaacsson ${ }^{2}$ 


\section{Resumo}

O texto investiga algumas modalidades da cena comumente denominadas de teatro do real. Espetáculos que acentuam tensões entre o real e o ficcional, presentes em qualquer representação. Inúmeras táticas e procedimentos são utilizados, dentre os quais se evidenciam a utilização do real como temática para a cena, ou enquanto linguagem, em prol de uma experiência real para o espectador. Em seguida, o espetáculo 100\% São Paulo do grupo suiço-alemão Rimini Protokoll é analisado a partir dessa ótica, levando em conta a revisitação de conceitos que elucidam processos contemporâneos ligados ao tema.

Palavras-chave: Ficção; performance; realidade; teatro do real.

\section{Abstract}

The text aims to investigate some scene modes commonly called theatre of the real. Spectacles that accentuate tensions between the real and the fictional, present in any representation. Numerous tactics and procedures are used, among which highlight the use of the real as a theme for the representation, or as language in favor of a real experience for the viewer. Then the spectacle $100 \%$ São Paulo swiss-german group Rimini Protokoll is analyzed from this perspective, taking into account the revisiting of concepts that elucidate contemporary processes related to the subject.

Keywords: Fiction; performance; reality; theatre of the real. 


\section{Introdução}

O fim da história para o filósofo italiano Gianni Vattimo (1987) é característica da pós-modernidade, que se abre para a multiplicidade de realidades existentes. O mundo explicado, analisado ou construído a partir de pontos de vista centralizadores, excluem a realidade dos outros, das diferentes culturas e modos de vida. Por conseguinte, passado e presente não podem mais serem pensados sem prever a existência da diferença - não como uma ameaça - mas como parte integrante da realidade. $\mathrm{A}$ história do homem não pode ser unívoca, excluindo inúmeras pessoas e povos que se encontram fora do eixo. Com o desenvolvimento dos dispositivos tecnológicos aliados à telemática, como aponta Vattimo, evidencia ser o mundo constituído de uma rede intrincada de idiomas e culturas diversos. Logo, o pensamento quando deixa de preocupar-se com as questões de alteridade, e não procura relações com a multiplicidade de olhares que constituem agora o real expandido e estilhaçado, não faz outra coisa senão fortalecer visões dominantes, unilaterais e ditatoriais. O fim da história é o da grande história e o início (ou consciência) das histórias. Percepção sempre ocultada ao longo dos tempos pela facilidade de controle dos meios de comunicação, agora colocada a descoberto pelo avanço tecnológico.

Por outro lado, no campo teatral, a criação e reflexão artística de modalidade cênica enquadrada na denominação de teatro do real tem aumentado substancialmente em nosso tempo. Teatros que nascem do contato com o real - seja como temática, seja como experiência - e pretendem de alguma forma reforçar essas premissas. Os procedimentos e estéticas que se valem dessa acepção são variados e servem para identificar teatros que incluem no seu interior algum elemento que remeta ao real factual: teatro documentário, teatro da realidade, biodrama, docudrama, site-specific, hiperrealismo, e todas modalidades de espetáculos que utilizam dados da realidade como elemento do discurso, muitas vezes explicitando essas fontes em cena. Incluem nos seus procedimentos desde a introdução de áudios, vídeos, documentos textuais, fotográficos, narrativas pessoais, testemunhos, entrevistas e cartas em cena, até a utilização de objetos ordinários, não-atores, mecanismos de distanciamento, entre outros. Patrice Pavis lembra, ao definir características do teatro documentário ao longo dos tempos, que a dramaturgia sempre recorre a fontes documentais (mitos, notícias, acontecimentos históricos), já que "nada surge do nada" e, por consequência, "se opõe a um teatro de pura ficção" (Pavis, 1999, p.387), todavia sabe-se que nem toda criação cênica tem a intencionalidade ou objetivo de documentar. Mas essa modalidade teatral é diversa, e pode existir através de ações que se valem do real enquanto linguagem, em prol de uma experiência real para o espectador, deslocando o terreno do teatro em direção ao campo da performance art. Estas geram táticas que acentuam o efeito de presença dos agentes cênicos, seja através de virtuose corporal, do risco físico de quem pratica, seja através do aumento da imprevisibilidade da cena organizada.

Antes de refletir sobre táticas sistematizadoras de um teatro do real, cabe aqui uma consideração que diz respeito a especificidades do acontecimento teatral; a singularidade do teatro em sua efemeridade, que convoca a presença de artistas da cena e espectadores em lugar e tempo pontuais da cidade, por si só, já inscreve o aconte- 
cimento no campo do real. Acontecimento cívico e político que somente existe para/ com a plateia. E a duplicidade dos elementos da representação no palco guardam sua dose de realidade através da tensão constante entre signos performativos e teatrais, como os atores que, em cena, "são golpeados por sua experiência concreta" (Pavis, 2010, p.184); não apagam sua identidade corpórea inteiramente em prol de um personagem. No caso do teatro dramático, o pacto implícito entre espectador e representação é determinante para que se acredite como verdadeira a história que se passa no palco da ilusão. Porém, basta que um erro fique aparente na interpretação dos atores, uma pequena escorregada no palco, um refletor que pisca e queima, para gerar um desvio do percurso do mundo perfeito elaborado, fazendo com que a realidade da vida retome seu lugar. O que se quer evidenciar aqui, e não é nenhuma novidade, mas que importa sumamente para esclarecer numa primeira instância, que todo teatro, independente do gênero ou estética, guarda em si, dada sua natureza, uma série de realidades inquestionáveis. Ou seja, a existência enquanto matéria concreta, bruta, seu significado prático no mundo, assim como a realidade da reunião presencial entre atores e espectadores. A duplicidade do signo teatral deixa implícito uma realidade intrínseca em qualquer acontecimento cênico. Partindo desse princípio, qualquer convocação cênica é considerada como teatro do real ou da realidade. Mas porque então definir a expressão teatro do real, na medida em que todo acontecimento cênico tem essa condição implícita nas suas bases?

\section{Teatro do real}

Então qualquer teatro se constitui de elementos reais, no que diz respeito a presencialidade dos encontros, mas também em relação à materialidade das substâncias que o compõem: o espaço do teatro (o palco ou outro lugar ressignificado), figurinos, cenários, adereços e etc. A expressão indica também que a ênfase de determinada poética tende a incidir sobre o terreno simbólico ligado ao mundo da materialidade da representação como um todo, da performatividade dos seus elementos em menor desvio possível do que se toma por real, em detrimento ou diminuição das ausências que são evocadas pela representação tradicional para que a ficção ocupe seu espaço. Nesse caso, a classificação de teatro documentário parece inapropriada ou incompleta nesse contexto, já que este não utiliza o real como fonte de experiência para além da constituição de uma narrativa.

A expressão teatro do real foi utilizada pioneiramente pela psicanalista francesa Maryvonne Saison, nos anos noventa, numa tentativa de diferenciar espetáculos que não se constituíam a partir do drama tradicional e, após a crise da representação, a partir do esteticismo de um teatro fechado em si. Segundo a autora, a realidade foi retratada em cena, ora através da imitação idealizada do mundo, ora através do desnudamento dos mecanismos teatrais e sua estruturação (Saison, 1998). Situando a discussão em época recente, opta por não levar em conta inúmeros indícios de utilização de elementos da realidade no teatro desde sempre, porque the interessa as implicações artísticas e sócio-políticas do gênero na contemporaneidade. Para a autora, duas maneiras se sobressaíram nessas vontades múltiplas de mostrar a realidade, de desmascarar o que se preferia manter escondido no teatro: 
A primeira consiste em colocar na cena através de documentos elaborados fora do teatro, uma certa representação de mundo. Outra, corresponde ao desejo de inscrever diretamente o teatro na realidade social, para dar a palavra aqueles que não puderam acessá-la (Saison, 1998, p.21)3.

Táticas que geram "efeitos de real" (Barthes, 1972), através dos testemunhos cênicos, espaços de apresentação e comprovação de relatos verídicos, retirados diretamente da realidade social e levadas ao palco. Aqui, a noção de realidade recai sobre o ato da enunciação, que poderia se dar através de atores desdobrando esses relatos na cena. Ou através da mobilização dos próprios excluídos sociais contra a exclusão, através de uma ação engajada e intervencionista, onde este adquire para si a palavra, em ações de experiência, encontro e alteridade colocados em cena. Para Saison, a busca dessa modalidade de teatro abriu espaço para uma espécie de arrombamento da realidade, através da colocação de elementos reais na cena, como os próprios excluídos sociais com suas histórias, corpos, vozes e expressividades específicos. Em vez de duplicar o ato pela sua representação, modificando o real, o que se pretendia era apresentar o real em estado bruto, a maneira do gesto emblemático e sempre citado de Marcel Duchamp no campo das artes plásticas, com seus ready-mades. $O$ teatro, ao importar a realidade bruta para cena, promoveu a tentativa de liberação de toda a mediação, de todo entrave estético. É dentro desta perspectiva, que pode se perceber inúmeros esforços teatrais recentes, de apresentar o real com o mínimo de desvio possível no teatro. Todavia, a difração, esse arrombamento da realidade se constitui como uma tentativa ingênua de apresentar o real na cena sem querer levar em conta todo o tecido representacional que envolve as artes e o mundo. Escapar de toda representação, do campo simbólico é algo impossível, tendo em vista que não só o teatro, mas a própria vida é tecida pela linguagem:

A obra cênica não é pura nem autônoma, ela nasce inserida em uma realidade, diretamente ligada a história do indivíduo e do mundo, e se apresenta sempre como uma modalidade de compreensão de si e do mundo, ou como uma modalidade de interrogação dessa construção (Saison 1998, p. 25 ) ${ }^{4}$.

A invasão do real na cena, pode ser percebida como resultado da crise da representação na modernidade, tendência já apontada por Lyotard (2002) e a crise das grandes narrativas do pós-modernismo. A realidade estilhaçada e caótica apresentada pelos meios de comunicação modernos, tornaram impossíveis os pontos de vista centrais, deixando evidente a pluralidade de versões do mundo. A representação tradicional, com sua visão única e totalizante baseada na fábula dramática já não dá

\footnotetext{
${ }^{3}$ No original: La première consiste à porter sur scène, à travers des documents élaborés en dehors du théâtre, une certaine représentation du monde; la seconde répond au souhait d'inscrire plus directement le théâtre dans la réalité sociale, pour donner la parole à ceux qui n'ont pu y accéder (tradução nossa).

${ }^{4}$ No original: L'oeuvre d'art n'est ni pure, ni autonome: elle naît insérée dans une réalité, elle est constamment en prise directe sur l'histoire de l'individu et du monde et se présente toujours comme une modalité de la compréhension de soi et du monde, ou plus encore comme une modalité d'interrogation sur la construcion possible de soi et du monde (tradução nossa).
} 
mais conta da polifonia contemporânea: "não existe mais uma imagem da realidade correspondente a um sistema coerente e ordenado, desenhando um mundo onde cada elemento tem seu lugar assinalado" (Saison, 1998, p.38) ${ }^{5}$. O luto de tal estética como forma de representação do mundo, do qual o modelo naturalista foi, segundo Peter Szondi no livro Teoria do drama moderno [1880-1950], seu último suspiro de vida, cedeu lugar a dramaturgia do eu, e ao teatro épico de Brecht, na segunda metade do século XX, e a posterior irrupção de realidades em cena. Se a verdade dos modelos totalizantes (iluminismo, idealismo e marxismo) se mostrou inoperante para entendimento do mundo, seu modelo tradicional de representação, que sempre a edificou, igualmente, precisou ser redimensionado. Mas, o teatro do real não foge da representação em direção ao real, ele percebe que este é uma construção, assim como o teatro também o é. Tensionar a realidade com a ficção possibilita adentrar o terreno do real sem abandonar o teatro, a realidade do teatro, algo já previsto pelo esteta alemão Bertold Brecht. Daí que através de teatralidades diversas, é possível perceber no acontecimento cênico contemporâneo, inúmeras táticas para circunscrever o real na cena.

Uma teatralidade possível é a utilização do real como temática, ao gosto do teatro documental, que parte de documentos históricos e biográficos, para criar dramaturgia e construir estreitamento entre arte e vida. $O$ teatro documental biodramático, por exemplo, utiliza elementos do real para alavancar ficção preparada e organizada. Modalidades que tendem a manipulação de temas que aderem ao real individual ou social-político específicos de cada tempo. Como o espetáculo gaúcho $O$ Fantástico circo- teatro de um homem só, da Cia Rústica, onde a vida pessoal do ator Heinz Limaverde foi utilizado como roteiro para a criação cênica. No espetáculo, ele narra, com os recursos da cena, seu passado, fazendo referência a acontecimentos e pessoas reais. Outra possibilidade é fazer do próprio acontecimento cênico um momento real, flertando diretamente com a performance. $O$ real experienciado a partir da cena pode advir pelo aumento no nível de imprevisibilidade da representação, onde o elemento do caos se instaura no interior do dispositivo cênico. O caos desagrega o mundo apolíneo da representação, fazendo com que emerja em cena uma certa vivência, onde artistas e audiência testemunham o real se atualizando ao mesmo tempo que a representação, suscetível a falhas, imprevistos e constrangimentos, no sentido de que não se sabe exatamente para onde as coisas podem ir. Pode ser provocado pelo atuante, animais em cena, dispositivos tecnológicos, entre outros procedimentos. A aparição do cavalo no espetáculo de teatro performativo Eu não sou bonita da Cia Atra Bilis Teatro, elaborado a partir de experiência real de abuso sexual sofrida pela própria encenadora espanhola Angélica Liddell, traz o risco de imprevisibilidade já que os animais não tem consciência de seus estado de performance, não sendo controláveis em

5 No original: II n'est plus question de croire à la possibilité de produire une image de la réalité correspondant à un système cohérent et ordonné, dessinant un monde ou un univers dans lequel à chaque élément reviendrait une place assignée (tradução nossa). 
sua totalidade. Essa espontaneidade e falta de consciência do seu lugar na representação faz com que o espontâneo, o imprevisto, e uma certa realidade se instaure como experiência. Quando se trata da possível desestabilização espetacular por conta do ator ou performer, cenas de violência, dor ou risco dão o tom da irrupção da realidade enquanto experiência, já que o perigo a própria integridade da vida aparece enquanto possibilidade. Na medida em que, em nome do simbólico, se investe com violência justamente no espaço fundamental pelo qual trespassam todos os demais elementos da representação - o corpo do artista. O deslocamento do terreno da representação para o campo do real curta circuita o ficcional, embaralha fronteiras, desorganiza contratos, como a própria Liddell cortando e sangrando seu corpo com uma lâmina. Pois é nesse contexto de multiplicidades de modelos de atravessamento do real, que se escolhe para examinar em especial a criação do grupo suíço-alemão Rimini Protokoll, recentemente apresentado no Brasil, dentro de um contexto de Festival.

\section{Rimini Protokoll}

A complexa poética do coletivo composto pelos alemães Helgard Haug, Daniel Wetzel, e pelo suíço Stefan Kaegi, oferecem exemplos de como o teatro do real opera, possibilitando verificar indícios de condição para que o mesmo exista, mas que não esgotam possibilidades e táticas de conformação desses espetáculos variados e plurais. O espetáculo a ser abordado faz parte do projeto intitulado $100 \%$ cities, e já percorreu 28 cidades de inúmeros países. Elenco composto por pessoas que vivem no local onde o espetáculo acontece, delineando o perfil coletivo populacional de uma cidade internacional, a partir de amostra quantitativa de individualidades. No Brasil, 100\% São Paulo foi apresentado dentro da programação da 3ạ Mostra internacional de teatro de São Paulo, em março de 2016. O espetáculo utiliza cenografia funcional: linóleo e tela circular para projeção, microfones em tripés, e arquibancada ascendente posicionada ao fundo do palco. A trilha sonora é realizada ao vivo por banda de samba-jazz posicionada nos camarotes laterais do teatro, que acompanha as movimentações dos participantes. O espetáculo inicia com um homem que informa dados estatísticos do Censo 2010 do IBGE (Instituto Brasileiro de Geografia e Estatística) relativos ao município de São Paulo. Todas as informações estatísticas podem ser acompanhas por livreto que a audiência recebe na entrada do teatro e que reforça o caráter de realidade do levantamento. A seguir, o palco é invadido por 99 pessoas, que foram selecionados de acordo com cruzamento entre distintas características populacionais ligadas ao sexo, idade, bairro, estado civil e cor. Eles apresentam à plateia suas identidades, através de microrelatos pessoais, traçando um panorama plural dos habitantes da cidade, e trazem consigo os mais diversos objetos como fotos, brinquedos, amuletos, livros, chapéus, e por vezes, seus filhos pequenos (gatos e cachorros foram levados ao palco em outras cidades por onde o projeto passou). Todos os escolhidos estão 
conectados afetivamente, uma vez que cada convidado apresenta o seguinte, alguém do seu círculo de relacionamentos, sugerindo que todos em uma cidade estão conectados de alguma forma, como uma grande família-comunidade. Ao longo de duas horas, os participantes, individualmente dão um passo a frente do coletivo, e iniciam um jogo de pequenos depoimentos pessoais, alternados com perguntas lançadas ao microfone, onde os demais precisam se posicionar espacialmente em resposta. Questões de gênero, religião, política, social, cultural e econômica vão delineando posicionamentos éticos e morais dos participantes. Em certo momento as perguntas, antes organizadas em um script, são liberadas, e a plateia é convocada a fazer parte do jogo cênico, seja realizando perguntas aleatórias aos que estão no palco, seja respondendo as perguntas lançadas a eles. Dessa forma se revelam as subjetividades particulares e, sobrepostas a estas, uma possível identidade coletiva.

\section{Teatro do real em $100 \%$ São Paulo}

O espetáculo não se estrutura a partir da forma dramática tradicional, não apresentando narrativa fabular coerente. O que se vê é a elaboração de jogos cênicos que variam em termos de estrutura, semelhantes a programas de auditório. Um mosaico composto de fragmentos narrativos diversos que se constituem através de testemunhos pessoais do participantes. Verifica-se uma irredutível pluralidade de versões de mundo nesses relatos, em consonância com o fim da história de Vattimo. Testemunhos que são reforçados por meio de materiais ordinários extraídos do cotidiano e levados à cena: fotos e objetos afetivos que conferem informações adicionais que atestam a inscrição dos fatos no campo da realidade dessas pessoas. O elenco é formado por não-atores. Corpos e ações despojados de princípios representacionais comuns ao teatro, que preservam marcas pessoais e culturais, através de fisicalidades não preparadas para a significação artificial de alguma técnica. Da criança ao idoso, passando por corporalidades específicas como deficientes físicos e transexuais, evidenciando a diferença como padrão da metrópole contemporânea. Como ready-mades de carne e osso, onde a identidade corporal é preservada, ao mesmo tempo em que a palavra é concedida ao outro.

Os diretores conceituam os participantes como "experts do cotidiano" (Mumford, 2013, p.153), pessoas que são especialistas nas suas próprias histórias de vida A noção deixa entrever que selecionados para os espetáculos possuem naturalmente determinadas características expressivas que conferem teatralidade a suas vidas. É possível perceber teatralidade em todo ser humano, se levarmos em conta que a teatralidade, segundo a pesquisadora francesa Josette Féral, é também a transformação do olhar de quem vê e identifica princípios expressivos no outro ou em alguma coisa: "[...] a teatralidade parece ser um processo, uma produção que está em relação inicialmente com o olhar, que postula e cria um espaço outro que se torna espaço do outro" (Féral, 
2015, p.86). O olho que teatraliza, que transforma o outro em "sub species theatralis" (Cornago, 2005, p.8). Os experts do cotidiano revelam algo de ator inato, graças a características específicas que os tornam interessantes no palco. Seja a partir dos seus corpos, a maneira de falar, histórias de vida potentes, algo que faz com que se destaquem da norma, legitimando que deem um passo a frente do coletivo e se apresentem no palco. Ligando este ao conceito mais tradicional de performance, próximo à "demonstração de certa habilidade" (Carlson, 2010, p.13). Logo, possuem qualidades expressivas implícitas que são percebidas pelo olhar dos diretores que os escolheram. Esse desejo de mostrar o real com menor desvio possível, apontada por Saison (1998), se confunde com a vontade de evidenciar a teatralidade inata do ser humano. A difração cria um jogo ambíguo que confere originalidade, organicidade ao que se passa no palco; instaura um potente efeito de real como consequência. Pode-se ainda perceber um grau de desordem durante a apresentação. Seja através da colocação de crianças em cena, seja através dos momentos de improvisação abertos, envolvendo tanto os participantes no palco, como a plateia, transformando o espetáculo em um jogo cênico que se compõe em tempo real na sua dimensão poética. $O$ dispositivo de perguntas e respostas instaurado, a medida em que avança, propõe a eliminação fronteiriça entre palco e plateia, incluindo o espectador em outras camadas do fazer artístico. Traz consigo um grau de deriva ao acontecimento, de imprevisibilidade narrativa pela experimentação, já que a apresentação não se constitui somente como universo fechado, mas que se abre em direção ao outro. É o próprio espectador quem constrói juntamente com o elenco esses momentos, onde determinadas hierarquias se dissolvem, se aproximando do que Dubatti classificou de abdução poética:

O lugar da expectação pode perder-se provisoriamente dentro de um jogo específico da poética teatral. O espectador pode sair do espaço de espectação e ingressar no campo do acontecimento poético de linguagem (Dubatti, 2003, p.23).

A noção de repetição como processo de fixação das cenas criadas dá lugar a uma repetição que expõe suas virtualidades. A obra acabada se transforma em obra processual, onde a experiência prevalece aos resultados. A ideia de expert do cotidiano se estende para ambos os polos da encenação tradicionalmente definidos e separados: ora se é plateia, onde se assiste ao acontecimento cênico, ora se é atuante, onde o homem comum reivindica para si a noção de protagonista por alguns segundos, espelhando o que se passa no palco, já que o elenco como um todo é uma mostra quantitativa de pessoas comuns que habitam a cidade. Esse deslocamento do coletivo anônimo, da escuridão homogênea de quem está posicionado na plateia para a posição de agenciador cênico, opera uma inversão momentânea nos papéis e na maneira de se dar o jogo estabelecido. Os elementos implícitos em qualquer evento teatral, como a reunião de pessoas em determinado tempo/espaço se amplifica pela democratização da criação, através de uma estética relacional que exige resposta. As 
experiências se configuram como ferramenta artística onde, por meio do teatro, se pode dar a conhecer a si, através do outro, trazendo consigo possibilidades de transformação crítica. Essa configuração aciona o teatro como instrumento de emancipação do indivíduo, pensando a arte como uma prática não restrita aos artistas, mas acessível a qualquer indivíduo. Nesse sentido, o espetáculo encontra o pensamento de Saison (1998, p. 19) : “[...] lutar por um espaço aberto, de respeito mútuo, espaço público comum de liberdades individuais e coletivas, de memórias e direitos" 6 . Dessa forma, o espectador no teatro do real não é mais aquele que recebe passivamente as informações unidirecionais do palco, à espera da catarse. Ele pode se transformar no próprio agente da ação, se obriga a tomada de posição frente ao que ele vê, mesmo permanecendo sentado na plateia. Quando o elenco senta na arquibancada situada ao fundo do palco cria um efeito de espelhamento em relação à plateia, sugerindo que o teatro do real quer, em última instância criar o efeito de identificação do espectador com o performer. Mas uma identificação mais direta, física, real, que não se dá através da construção de ausências do personagem ficcional. Se o ciclo biodramático coloca no palco histórias pessoais, levando em consideração o indivíduo como porta voz da sua realidade, em $100 \%$ cities, os indivíduos são porta-vozes da coletividade como um todo, circunscrito a cidade na qual o espetáculo se apresenta. Em 100\% São Paulo, as possibilidades do real no palco como temática e como experiência se cruzam e se potencializam, questionando a representação a partir da colocação de outras maneiras de construção de teatralidades, o que não significa que essa ação se dê pelo simples confrontamento com a representação dramática clássica. Mas através da evidenciação da multiplicidade de maneiras de representar, assim como existem inúmeras maneira de perceber o real em um mundo de realidades múltiplas.

\section{Referências}

BARTHES, Roland et al. O efeito de real. In: Literatura e Semiologia: Pesquisas Semiológicas. Petrópolis: Vozes, 1972, pp.35-44.

CARLSON, Marvin. Performance. Uma introdução. Belo Horizonte: UFMG, 2009.

CORNAGO, Óscar. Biodrama: sobre el teatro de la vida y la vida del teatro. Latin American Theatre Review, Kansas, n. 39, 2005.

Disponível em https://journals.ku.edu/latr/article/view/1515 . Acesso em: 20 dez. 2016.

DUBATTI, Jorge. El convivio teatral. Teoria y práctica del teatro comparado. Buenos Aires: Atuel, 2003.

${ }^{6}$ No original: [...] lutter pour un espace ouvert, pour le respect mutuel, pour ne pas cesser de bâtir l'espace public commun des libertés individuelles et colectives, des mémoires et des droits (tradução nossa). 
FÉRAL, Josette. Além dos limites: teoria e prática do teatro. São Paulo: Perspectiva, 2015.

LYOTARD, Jean-François. A condição pós-moderna. São Paulo: José Olympio, 2002.

MUMFORD, Meg. Rimini Protokoll's Reality Theatre anda Intercultural Enconter: Towards

Ethical Art of Partial Proximity. Contemporary Theatre Review. Londres: Routledge, 2013.

PAVIS, Patrice. A Encenação Contemporânea. São Paulo: Perspectiva, 2010.

PAVIS, Patrice. Dicionário de Teatro. São Paulo: Perspectiva, 1999.

SAISON, Maryvonne. Les théâtres du réel. Pratiques de la représentation dans le théâtre contemporain. Paris: L'Harmattan, 1998.

SZONDI. Peter. Teoria do drama moderno [1880-1950]. São Paulo: Cosac \& Naify, 2001.

VATTIMO, Gianni. O Fim da Modernidade. Niilismo e hermenêutica na cultura pós-moderna. Lisboa: Editorial Presença, 1987. 